Karakuş Umar, Esra (2019). “Sosyolojik Bakış Açısından Gıda Güvencesi Kavramı”. Uludağ Üniversitesi Fen-Edebiyat Fakültesi Sosyal Bilimler Dergisi, C. 20, S. 37, s. 1027-1046.

DOI: $10.21550 /$ sosbilder.512834

Araştırma Makalesi

\title{
SOSYOLOJIK BAKIŞ AÇISINDAN GIDA GÜVENCESİ KAVRAMI
}

\author{
Esra KARAKUŞ UMAR*
}

Gönderim Tarihi: Ocak 2019

Kabul Tarihi: Mart 2019

\section{ÖZET}

Temelde gıda güvencesi, bir insanın yaşamını sürdürmesi adına tüketmesi gereken gıdaya ulaşabilmesine karşıllk gelmektedir. Bir sosyal hak olarak gıda güvencesi, küreselleşme ile bireyin tüketim tercihlerine bırakılmıştır. Neo liberal politikaların etkisi ile yükselen bireyselleşme de devletlerin, vatandaşlar için gıda güvencesi sorumluluğunu üzerinden almış ve vatandaşların, kendi gıda güvencesini kendisinin sağlaması gerektiği bir alan yaratmıştır. Üreticinin, üretim sürecinden uzaklaştırllırken gıda güvencesini sağlaması sadece satın alma davranışı üzerinden yürütülebilecek gibi görünmektedir. O halde Türkiye özelinde gıda güvencesi kavramı, daha geniş çerçeveden yorumlanmalıdır. Söz konusu çerçevenin sinırları da çalışmanın konusunu belirlemektedir. Buna göre; "küresel şirketlerin hızla söz sahibi olmaya başladı̆̆ tarım topraklarında, gıda güvencesinden bahsedilebilir mi?" ve "köysüzleşen nüfus, gıdayı kendisi üretiyorken üretim sürecinden kopmuşsa gıdaya ulaşım şekli nasıldır?" soruları gıda güvencesinin, Türkiye için sosyolojik bir çerçeveden yorumlanması gerektiğini ortaya koymaktadır. Bundan dolayl gıda güvencesi kavramı çalışmamızda "mülksüzleşme", "köylü-işçi”, "iç göç" ve "kentleşme" kavramlarından yola çıkılarak anlaşılmaya çalışılacaktır.

Anahtar Kelimeler: gıda güvencesi, tarım, kentleşme, iç göç

* (D) Dr. Öğr. Üyesi, Atatürk Üniversitesi Oltu Beşeri ve Sosyal Bilimler Fakültesi Sosyal Hizmet Bölümü, esra.umar@atauni.edu.tr

Uludağ Üniversitesi Fen-Edebiyat Fakültesi Sosyal Bilimler Dergisi Uludağ University Faculty of Arts and Sciences Journal of Social Sciences Cilt: 20 Sayl: 37 / Volume: 20 Issue: 37 


\section{Food Security Concept from a Sociological Perspective}

\section{ABSTRACT}

Individualization rising under the effect of neo-liberal politics abdicated responsibility of food security for citizens given by the state and created a new zone where citizens need to provide his or her own food security. Food security as a social right is left to the individual's consumption preferences through globalization. Basically food security corresponds to having access to food needed for survival. Providing food security by producer while being suspended from production process can seemingly be performed over his or her buying behavior. Therefore, the concept of food security specific to Turkey must be evaluated from a broader perspective. The limit of this perspective specifies the subject of this study. Accordingly, the questions 'Can food security be mentioned in agricultural soil where global companies started to have a corner promptly?' and 'What are the ways of accessing food by deruralized population suspended from production process while they produce food themselves?' reveals the need to reinterpret food security for Turkey from a sociological perspective. Consequently, food security concept will be studied on the basis of 'dispossession', 'peasant-worker', 'domestic migration' and 'urbanization' terms.

Key words: food security, agriculture, urbanization, internal migration

\section{Giriş}

Tarih boyunca gıdanın yetiştirilebileceği verimli topraklara ulaşma isteği kanlı savaşlara ve isyanlara sebep olmuştur (Kıymaz vd. 2010: 2). Ayrıca üretim yapılacak toprakların da ürün vermesi için doğa koşullarına bağlı olması insanlar için belirsizlik ve korku kaynağı olmuştur. Üretim yapılacak topraklara sahip olunması ve üretimin de sağlıklı bir şekilde sağlanması durumunda ortaya çıkan ürünün hasadı ile birey, tüm yıl ihtiyacı oldukça kullanabileceği ürünü elde edebilmektedir. O yılın ürünü aynı zamanda gelecek yılın tohumunu sağlamakta ve sürekliliğe hizmet etmektedir. Doksanlı yıllara kadar üretim ve saklama sürecinde yaşanan belirsizliklerde devlet, üreticinin yanında durmuş ve üreticinin belirsizliklerle başa çıkmasında yardımcı bir güç olarak var olmuştur. 
Son yıllarda verimli topraklara ulaşma fikri, ülkeler arasında kanlı savaşlara neden olmak yerine daha farklı yöntemlerin kullanmasına neden olmaktadır. Shiva (2014), "çalınmış hasat" isimli çalışmasında Hindistan'daki köylünün küresel şirketler için çalışan çiftçilere dönüşme sürecini anlatır. Öyle ki Hindistan'ın sahip olduğu verimli topraklarda köylü, kendi ürettiği ürüne yabancılaşmıştır. Çiftçi küresel tohum ve ilaç şirketleri tarafından borçlandırılmıştır. Öyle ki bu borçlanma neredeyse tüm ömrü boyunca yapacağı üretimle bile kapanamayacak duruma gelmiştir. Neticede verimli topraklar hala Hindistan'a aittir ancak ürünler, küresel gıda arzının bir parçası durumundadır. Dolayısıyla verimli topraklara ulaşmak, artık küresel pazar için kan dökülmesini gerektirmeden yeni yolların bulunmasına vesile olmuştur.

Üretim alanında kullanılan teknolojilerle birlikte üreticinin korkusu olan doğayla da baş edilmiştir. Teknolojik gelişmelerle birlikte doğayla başa çıkmanın yanında üretim de önemli sıçramalar yaşanmıştır. Öyle ki genetiği değiştirilerek üretilen tohumlarla ne kadar sürede ne üretileceği kestirilebilir bir hal almıştır. Ayrıca teknolojik gelişmeler, üretim koşullarında doğanın etkisini kontrol edebilmenin yanında hasat sonunda da ürünlerin saklanması ve dağıtımı anlamında önemli gelişmeler sağlamıştır.

Son olarak neoliberalleşmeyle başlayan süreç, devlet desteğinin piyasadan çekilmesine neden olmuştur. Neticede piyasalar ve üretilen teknolojiler gıda üreticisinin belirsizliklerle başa çıkmasında yardımcı olur gibi görünmektedir. Küresel şirketlerin girişimciliklerini serbest bir şekilde yapabilmelerinin önemli bir yolu da devlet müdahalesinin ortadan kalkmasıdır. Ancak destek ortadan kalktıkça gıda üretimindeki belirsizlik yeniden gündeme gelmiştir (Kiymaz vd. 2010: 2). Ancak bu belirsizlikler önceki dönemdeki gibi doğa koşullarıyla alakalı olarak değil üreticiler ve küresel tohum sektörünün üreticinin başına açtığ 1 yeni belirsizlikler olarak karşımıza çıkmaktadır. 
Ortaya çıkan sıkıntılar artık doğa koşullarına tümüyle bağlanamamaktadır. Ayrıca toprak hâkimiyeti ile üretimin yapıldığ 1 yere ait olduğu ve orada tüketileceği fikri de ortadan kalkmıştır. Bu sebeple gıda güvencesizliğinin sebebini başka yerlerde aramak gerekmektedir. Magdoff (2015), gıda güvencesizliğinin temel sebebini serbest piyasada görmektedir. Serbest piyasanın devletin müdahaleci tavrını engellemesi ve devleti üretim süreçlerinden uzaklaştırması küresel şirketlerle üreticiyi karşı karşıya getirmiştir. Dolayısıyla bugün yaşanan küresel gıda krizlerinin sebebi de küresel şirketlerin kar elde etmek adına köylüyü üretim alanlarından uzaklaştırması ya da işçisi olarak çalıştırması olarak düşünülebilir.

\section{Materyal ve Yöntem}

$\mathrm{Bu}$ çalışmada; gıda güvencesi, tarım, kentleşme ve iç göç ile ilgili yapılmış akademik çalışmalar incelenmiştir. Ayrıca çeşitli kurum ve kuruluşlara ait istatistikler üzerinde çalışılarak sosyolojik anlamda gıda güvencesi kavramı, tarımdan kopan nüfus ile kentleşme ve göç olgusu üzerinden değerlendirilmiştir. .

\section{Gıda Güvencesi Kavramı}

Gıda güvencesi kavramı ilk olarak 1996 yılında Dünya Gıda Zirvesinde gündeme gelmiştir. En temelde gıdanın piyasalarda bulunuyor olması ve tüketicinin de ya kendisinin üretimi yoluyla ya da piyasalar aracılığıyla ulaştı̆̆ Kavramın karmaşıklığ 1 ise sürdürülebilir bir zeminde tartışılmadığ için gıda güvencesinin risk içermesinden kaynaklanmaktadır. Neticede gıda güvencesi artık doğal koşulların izin vermemesi ile tehlikeye giren bir süreç olmaktan çıkmış ekonomik, sosyal ve siyasi süreçlerin uygulama alanı olmuştur.

Kavram, gıdaya erişim güvencesini tanımlarken temel ilkelerden yola çıkılmaktadır. "Sağlanılabilirlik" ilkesi herkese yetecek gıdanın üretilmesi ve bozulmadan tüketiciye ulaşmasını içerirken fazlalığın da etkin bir şekilde korunması konularını içermektedir. "Erişilebilirlik" 
ilkesi ise tüketicilerin yeterli gelire sahip olmalarını işaret ederken yeterli gelire sahip olmayanların da devletin desteği ile gidaya erişebilmesini ifade etmektedir. "Kabul edilebilir olması" ise gıdaların sağlıklı olmasını ancak kültürel açıdan da uygun ürünlerin sağlanmasını temsil etmektedir. "Yeterlilik" ilkesi ise bugünkü üretim faaliyetlerinin gelecek nesillerin de gıdaya ulaşmasını engellemeyecek şekilde sağlanmasını içermektedir (Koç 2013: 16-18). Gıda güvencesinin hesaplanması ile ilgili uluslararası çalışmaların sayıları artmaktadır ancak gıda güvencesini tam olarak temsil edebilen bir hesaplama yöntemi üzerinde uzlaşma sağlanamamıştır. Ayrıca yapılan hesaplamalarda gıda güvencesinin, sağlanılabilirlik ve erişilebilirlik boyutları açıklanırken kabul edilebilirlik ve yeterlilik boyutları ihmal edilmektedir (Koç vd. 2018: 978).

Gıda güvencesi, doğa koşullarından tamamıla bağımsız değildir. Ancak özellikle son yıllarda yaşanan teknolojik gelişmeler, doğa koşullarını kontrol altına alabilmenin olanaklı olduğunu göstermektedir. Bunun yanında yaşanan ekonomik ve siyasi gelişmeler de gıda güvencesinin sadece doğaya bağlı olmadığını aynı zamanda toplumsal bir sürece de tabi olduğunu göstermektedir. Gıda güvencesinin sağlanmaması, açlı̆ga sebep olduğundan ulusal ve uluslararası düzeyde yapılan birçok plan ve program bu konuda çalışsa da kalıcı bir çözüme ulaşılabilindiği söylenemez (Erbaş vd. 2015: 5159).

Türkiye'de gıda güvencesini tehdit eden etmenleri araştırdıkları çalışmalarında Yalçın vd. (2016), iklim değişikliği ve kuraklık, tarımsal üretim kaynaklı etmenler, kırdan kente göç, biyo-yakıt kullanımı, eğitim ve işgücü, girdi ve ürün fiyatları, yoksulluk ve yüksek gıda fiyatları ile tarım politikaları konularından hareket etmişlerdir. Ağaç (2011) yüksek lisans çalışmasında gıda güvencesinin sağlanamamasını, ekonomik bir sebebe yani kapitalizmin gelişimine bağlamaktadır. Bu konuda çalışma yapan Boratav (1980: 74) kapitalizmin, tarımda küçük üreticinin ortadan kalkmasına neden olduğunu vurgulamaktadır. $\mathrm{Bu}$ 
noktada "Kapitalizm, gıda güvencesinin sağlanabilmesinin karşısında mıdır?" şeklinde soru sorulduğunda aslında gıda güvencesinin temelinde tüketim kültürü etkisinin olduğunu kabul edersek böyle bir amacının olmadığı sonucuna da varılacaktır. Neticede kapitalist ekonomi, nüfusun daha çok tüketmesini isteyecektir. Zira gıda güvencesi kavramı tanımda bu görülebilir. Gıda güvencesi bireyin gıdayı rahatlıkla tüketmesi için tüm koşulların seferber edilmesini ifade etmektedir.

\section{Türkiye'de Tarımın Tasfiyesi}

Yirminci yüzyılın iktisat tarihçisi Hobsbawn bu yüzyılın ikinci yarısında bizi geçmişin dünyasından koparan bir gelişmenin meydana geldiğinden bahseder. Bu gelişme, köylülüğün ölümüdür. Söz konusu yıllarda yani 80 'li yılların başında dünyada köylülüğün ölümünden bahsedilirken Türkiye'de o dönemde mutlak bir çoğunluk tarımla uğraşmaktadır. $\mathrm{Bu}$ durum Türkiye'nin, "köylü kalesi” olarak nitelendirilmesine neden olmuştur (Köymen 2008: 10).

Türkiye'de 80'li yıllarla birlikte dönüşüme başlayan süreç dünyada önceki dönemlerde yaşanmıştı. Özellikle 80'li yıllara gelindiğinde Türkiye ile Orta ve Güney Amerika arasındaki farklılık gözle görebilir derecedeydi. Keyder vd. (2015: 111), tarımda diğer ülkelerden farklılaşmamızın sebebini yabancı şirketlerin Türkiye'deki etkinliğinin önemsiz derecede olmasında görmektedir. Aynı dönemde Orta ve Güney Amerika'da tarım sektöründe yabancı sermayenin yatırımları Türkiye'ye kıyasla yüksek seviyelerdeydi. Örneğin Venezuela'da buğday işleme sektörünün tamamına yakınını iki Amerikalı şirket (International Milling ve Pillsbury) ve bir yabancı ortaklı şirket (Bunge and Burn / General Mills) kontrol etmekteydi.

Türkiye'de süreç 80'li y1llarla başlasa da küresel krizle aynı özellikler göstermektedir. Tarımsal üretimde yatırımların ihmali önemli bir detay olarak karşımıza çıkmaktadır. Özellikle küçük üreticinin pazardan çekilmesine neden olan bu süreç tarımsal üretimde serbest 
ticaret fikri ile paralel gittiğinde ithalatın patlamasına neden olmaktadır. Devletin tarım üzerindeki rolünün azalması süreç üzerinde etkili olabilecek düzenleyici elin de ortadan kalkmasına neden olmaktadır. Koç (2013: 79), dünya gıda piyasasındaki ücretlerin düşüklüğüne aldanarak yapılan gıda ithalinin, tarım sektörünün ihmal edilmesine neden olduğunun, sonuç olarak da uzun vadede ithalatçı ülkede gıda güvencesinin riske gireceğinden bahsetmektedir.

Küçük üreticinin üretimden çekilmesi ve küresel on büyük şirketin tüm tohum piyasası üzerinde söz sahibi olması birbiri ile bağlantılı iki durumdur. Bu durumun sosyolojik sonucu ise yoksulluk oranının yükselmesi, işsizliğin artması, kırdan kente göçlerin yaşanması şeklinde siralanabilir. Öyle ki üreticiler kendi ürettikleri ürüne yabancılaşmakta ve Hindistan örneğinde olduğu gibi çiftçilerin tüm hayatları boyunca çalışsa bile ödemeyecekleri bir borç yükünün altında kalmalarına neden olmaktadır (Shiva 2014). Bu duruma bir örnek de Meksika'dır. Üretilen gıda, küresel pazara hizmet ederken Meksikalı üreticinin aşırı yoksullukla mücadele ettiği bilinmektedir (Topal 2014).

Dünyada olduğu gibi Türkiye'de de köylü ve çiftçi kavramları tartışılmaya başlanmıştır. Owen (2005: 371), bir ülkenin modernliğinin, köylünün ortadan kalkması ile mümkün olabileceğinden bahseder. Ancak bu şekilde bir toplumun geleneksel yapıdan koptuğu söylenebilir. $\mathrm{Bu}$ noktada köydeki nüfusun işçileştirilmesi de gerekmektedir $\mathrm{ki}$ bu da planlanan durumun, sosyal hayata uyumlanamadığını bize göstermektedir. Burada köylü kesimin üreteceğinden daha fazla üretecek çiftçi, köylünün elindeki verimli topraklara sahip olmak adına küresel şirketler tarafindan kullanılmaktadır. Ayrıca kredilendirilme ile borçlandırılan köylü, aldığı ürünle borcunu karşllayamamakta ve topraklarına el konularak mülksüzleştirilmektedir (Bozoğlu 2018: 32).

Türkiye'de tarımda çalışan nüfusun toplam çalışan nüfus içerisindeki payı, 1991 yılı verilerine göre \% 48 iken 2017 yılındaki 
verilere göre \% 19,0'a gerilemiştir (TÜİK 2017). Dünyada tarımda çalışan nüfusun payı ise, 1991 verilerine göre \% 43,3 iken 2017 yılında $\%$ 26,5'e gerilemiştir. Avrupa'da ise Türkiye ve dünya ile paralel olarak 1991 yılında \% 9,8 iken 2017 yllında \% 4,2'e gerilemiştir (ILO 2018 akt. İTB 2018). Söz konusu verilerde dikkati çeken ayrıntı ise Türkiye'nin Dünya ve Avrupa ile kıyaslanamayacak derecede iyi bir oranla tarımla uğraşırken tarımla uğraşan nüfusun, dünyada tarımla uğraşan nüfus oranının bile gerisine düşmesidir (Bozoğlu 2018: 30).

\section{Kırsal Göç ile Üretimden Uzaklaşan Birey}

Türkiye'de iş̧̧inin ortaya çıkması diğer ülkelerde işçi sınıfının oluşmasından bağımsız olarak değerlendirilmelidir. Köylülerin iş̧̧i sınıfına eklemlenme süreci diğer ülkelerde kapitalizmin gelişim süreci üzerinden düşünülürken; Türkiye'de feodal yapının olmayışı ve Osmanlı'nın toprak anlayışı, bu sürecin farklı şekilde yorumlanması gerektiğinin altını çizmektedir.

Dünya tarihinde köylü, mülksüzleşerek yani kendi üretim aracını, toprağını kaybederek işçiliğe yönelmektedir. Ancak Türkiye'de köylünün özellikle de kente göç etmesinden yani işçi olarak değerlendirilmesinden sonra bile köyünde kendine ait küçük de olsa toprağı olduğu bilinmektedir. Bu durum "köylü-işçi" ifadesinin Türkiye örneği için daha uygun bir ifade olacağını düşündürmektedir (Yıldırmaz 2014: 48). Dünya tarihinde işçi sınıfının oluşumu, köylülükten kopan işçi için daha anlamlıdır ve bir bilinç meselesidir. Ancak Türkiye gerçeğinde köylü, toprağını ekerken aynı zamanda köye yakın bir fabrikada işçi olarak da çalışabilmektedir. Dolayısıyla işçi ve köylü ayrımının net bir şekilde yapılması ve bu süreçlerin birbirinden ayrılan ifadelerle tanımlanması zordur.

Bugün Türkiye'de köylü, köylü-işçi kavramından uzaklaşmaktadır. Köylü artık sadece işçi olarak hayatına devam etmeyi düşünerek kırdan kente göç etmektedir (Öztürk vd. 2008). Kırsal göçü işaret eden çalışmalar, 1980 sonrasında artmıştır. Bunun sebebi de 
kentli nüfusun, kırsal nüfusu geçmesi olarak değerlendirilmiştir (Özer 2004: 51). Söz konusu çalışmalarda köylünün kente göçü sırasında köylü-işçi olduğu göz ardı edilmiştir. Köylünün tam bir şekilde kente göç ettiğinden bahseden çalışmalarda köylünün mülksüzleştirildiğinden bahsedilir. Makine sahibi olan köylüler, topraklarını genişletmek adına "ortakçı ya da yarıcı" olarak tanımladıklarını üretimden çıkarmışlardır. 1982 yilında Kiray (1982: 122-123) tarafindan yapilan bu değerlendirme, dönemi için açıklayıcı olsa da köylünün kente gitmesine rağmen köyü ile sürdürdüğü bağını açıklamamaktadır.

Öztürk vd. (2008), Türkiye özelinde iç göçün sebeplerini inceledikleri araştırmalarında tarımın öneminin altını çizmektedir. Tarım politikaları, tarım topraklarının miras için bilinçsizce parçalanması ve ekilecek tarlanın darlığı, tarımda teknolojinin gelişmesi ve doğal afetler tarımla uğraşan kesimi olumsuz etkileyerek onları açlığa ve işsizliğe sürüklemiştir. Neticede üretim sürecinden vazgeçen birey, gıdaya birinci elden ulaşmak yerine para kazanmaya ve gıdayı satın almaya itilmektedir. Burada dikkat edilmesi gereken husus, Türkiye'de iç göçlerin sebep olduğu gıda güvencesizliği, kentin çekiciliğinden ileri geliyor gibi görünse de temelinde kırsal yapının bireyi itmesiyle ortaya çıkar. Bu noktada tüm dünyada olduğu gibi kentte var olan ekonomik etkinliklerin ya da gelişen sanayinin işçileri kente çağırması durumu, Türkiye'de söz konusu değildir. Kentte, birikimsel ve dengesiz bir durumun oluşması da bundadır (Özer 2004: $50)$.

Kırdan kente göç ederek farklı iş kollarında çalışan birey, tarımda üretim sürecinden uzaklaşmaktadır. Yaşanan kırsal göçle birlikte tarımda çalışan işgücünün azalması, terk edilen ve ekilmeyen arazinin atıl bir şekilde kalması ile üretimin ve verimliliğin düşmesi ayrıca üretimde yaşanan sıkıntılardan dolayı yoksulluğun artması sorunları da göçün kırsal alanda yaşanan sonuçları olarak görülebilir (Yalçın vd. 2016: 1). 


\section{Eski Küçük Üretici, Yeni Tüketici}

$\mathrm{Bu}$ kısımda üretim sürecinden uzaklaşan küçük üreticinin kentlere yönelerek iş̧̧ileşmesi sonucu söz konusu bireyin gida güvencesi durumu incelenmiş̧ir. Küçük üretici kavramı, üreticinin sahip olduğu toprak büyüklüğü ile ilgili bir kavramdır. Orta Avrupa ölçülerinden yararlanan Aç1l (1957: 113)'ın çalışmasında 1-500 dönüm arasındaki tarım toprakları küçük; 500 dönüm üzeri tarım toprağı ise orta ve büyük üreticinin toprağı olarak kavramsallaştırılmaktadır. Ayrıca küçük işletmeleri kendi içinde sınıflandıran Öktem (1966: 64) çalışmasında, 100 dönüme kadar olanlara küçük; 100-200 dönüme sahip olanlara orta ve 200-500 dönüm arazi işleyen işletmelere de büyük köylü adını vermiştir.

“Trakya Bölgesi 2014 - 2023 Bölge Planı” çalışmasında tarımda daha az işgücüne ihtiyaç ile arazi fiyatlarının artması ve arazi büyüklüğünün ekonomik sürdürülebilirlik açısından yeterli olmamas1 nedenlerinin, Trakya'da gençlerin tarımdan kopmasına ve üretici konumuna yeniden gelmek istemeyerek kente göç etmelerine sebep olduğu sonucuna varılmıştır ${ }^{1}$. TEPAV (Türkiye Ekonomi Politikaları Araştırma Vakfi) Antalya'da yaptığı çalışmada 2018 yılında 5 bin işçinin tarımı bıraktığı, tarımı bırakan nüfusun da turizm ve kamuya geçtiği sonucuna varmıştır. Söz konusu nüfusun yeniden tarımsal faaliyetlere dönmeye niyetli olmaması da çalışmanın sonuç kısmında belirtilmiştir (Hürriyet, Erişim Tarihi: 01.12.2018). Söz konusu iki örnekten de anlaşılacağ gibi küçük üreticiler, çeşitli sebeplerle tarımdan kopmakta ve yeni iş kollarına yönelmektedirler.

Tarımdan kopan nüfusun hizmet kollarına yönelmesi durumunda işsizliğin söz konusu olması doğaldır. Neticede ekonomik sorunlar sebebiyle hizmet sektörü kendi işçisini bile gözden çıarmaktadır. Ayrıca teknolojik gelişmelerin de etkisi ile insan gücünün gerektiği

${ }^{1}$ www.yesilvadiarsaofisi.com.tr (Erişim Tarihi: 11.12.2018)

Uludağ Üniversitesi Fen-Edebiyat Fakültesi Sosyal Bilimler Dergisi Uludağ University Faculty of Arts and Sciences Journal of Social Sciences

Cilt: 20 Sayl: 37 / Volume: 20 Issue: 37 
üretim ortamı yerini makine ve teknolojik ürünlere bırakmıştır (Kazgan 1994: 112). Özkaya tarafından 1996 yılında İzmir'de küçük üreticiyi konu aldığı çalışmasında küçük üreticinin yerine sıklıkla büyük işletmelerin desteklendiğini söylediklerini belirtir. Burada küçük üretici, devlet tarafından desteklenmediğini düşünürken desteğin büyük işletmelerden yana olduğunu belirtmektedir. $\mathrm{Bu}$ noktada sorunun seksenler sonu doksanlar başından başladığı ve küçük üretici ile büyük işletmelerin arasındaki farkın söz konusu yıllarda başladığı söylenebilir ancak çalışmanın yapıldığı tarihlerde üreticinin göçü düşünmediği sadece topraksız olan köylünün göç fikrini değerlendirdiğini vurgulamaktadır.

Yaklaşık otuz yılda küçük üretici ya da işletme sahipleri göç konusuna daha sıcak bakmaya başlamıştır. Yalçın vd. 2016 yılında küçük işletme sahiplerinin göçe yönelme sebeplerini şöyle açıklamaktadır; "küçük işletmelerden oluşan Türk tarım yapısında, üretim girdilerinin küçük işletmelerde birim maliyetleri artmıştır. Buna karş11ık piyasada oluşan düşük ürün fiyatları, desteklemelerden yararlanmada yaşanılan sıkıntılar, küçük işletmeler için cazip olmayan koşullara sahip tarımsal krediler tarımı itici hale getirmiştir" (Yalçın vd. 2016: 156).

Tarımın iticiliği, bireyleri üretimden uzaklaştırmakta ve üretileni tüketen haline getirmektedir. Yeni tüketiciler için kent, ilgi çekici görünmektedir. Pınarcıoğlu vd. (2012), “nöbetleşe yoksulluk" kavramını kullanarak "kent içi yoksulluk" kavramının Türkiye'de farklı bir anlam yarattığ 1 olgusunu açıklamaktadırlar. Nöbetleşe yoksulluk, üreticilerin yeni birer tüketici olarak kente uyumlanmalarını sağlamaktadır. Neticede kente uyumlanamama ve sosyal dışlanma yaşama sonunda bireyin sistemde iş piyasasına katılma şansı ortadan kalkmaktadır. Bireyin tüketici olarak hayatına devam etmesi önemli bir detay olarak karşımıza çıkmaktadır. Bu konuda Baudrillard (2004) yeni dünya düzeninin tüketim kültürü odaklı olmasından kaynaklı sorunların yaşandığından bahseder. Birey, tüketim kültürüne uyum sağlamak için 
tüketmelidir. Tüketememesi ise onun hiçbir sınıfa ait olmasına yani "sınıfaltı" olmasına neden olacaktır. İşte nöbetleşe yoksulluk, tarımdan kopan nüfusun kente gelmesi ile kente uyumunu sağlamaktadır. Bu da kendinden önce kente gelen nüfusun para kazanmak adına kendinden sonra gelen nüfusu aracı olarak kullanmasından ileri gelmektedir.

\section{Ya Topraksız Köylüler?}

Buraya kadar kırsal alanda yaşayan ve çeşitli sebeplerle toprağından ayrılarak iç göç yolunu tercih eden kişiler üzerinden ilerleyen gıda güvencesi sorununa son olarak topraksız köylü açısından da bakmak gerekmektedir. Tek partili dönemden itibaren yerine getirilemeyen düşünce olan toprak reformu, Mustafa Kemal'in siklıkla üzerinde durduğu bir olgu olarak karşımıza çıkmaktadır. Toprak reformu, kısaca topraksız köylüyü toprak sahibi etmek adına toprakların yeniden paylaştırılmasını içermektedir ancak söz konusu projenin hala hayata geçirildiği söylenememektedir.

Topraksız köylüler, tarımda makineleşmeden en çok zarar gören kesim olarak karşımıza çıkmaktadır (DİE 1973: 70; Tütengil 1975: 90). Sonuçta tarımda makineleşme ile birlikte topraksız köylüyü köyünde tutacak sebep ortadan kalkmıştır. Köyde yeni bir iş alanı sağlanmadığı sürece topraksız köylünün iş için göç yolunu seçmesinden başka bir çaresi kalmamış gibi görünmektedir. "1948 - 1957 yılları arasında tarım sektörüne giren 40.000 traktör 160.000 aileyi başka bir deyişle 800.000 kişiyi kentlere göç etmeye zorlamıştır. 1950 ve 1955 yılları arasında tarımın makineleşmesi sonucu 350 bin çiftçi ailesinin işlerini kaybettiğini iddia etmektedir." (Koyuncu 2011: 57).

$\mathrm{Bu}$ süreçte belirtilmesi gereken sadece topraksız köylünün değil büyük şirketlerin tarım sektörüne geçişi ile birlikte küçük üreticinin de toprağını bırakarak göç etmesidir. Dolayısıyla büyük toprak sahipleri karşısında küçük üretici ile topraksız köylünün konumu eşitlenmiştir (Koyuncu 2011: 56). Teber tarafından yapılan çalışmada, 1980 yılında tüm köy nüfusunun \% 86,2'sini oluşturan bu grubun tarım topraklarının 
sadece \% 28'ine sahip olduğudur (Teber 1980: 51). O halde belirtmek gerekir ki topraksız köylü ile küçük üretici arasındaki fark "göç" konusuna yansımamıştır. Neticede miras yolu ile toprakların bölünmesi ya da küçük üreticinin topraklarını büyük üreticiye satış1 gibi durumlarla toprak mülkiyetinde "kutuplaşma" bireyleri üretimden kopararak göçe sürüklemiş̧ir.

\section{Sonuç ve Tartışma}

Gıda güvencesi kavramına Türkiye özelinde sosyolojik açıdan yaklaşıldığında, iç göç sonucu ortaya çıkan kentleşme ve üretim sürecinden uzaklaşan küçük üretici ve tüketime odaklanan işçi kavramları dikkati çekmektedir. İç göç ve kentleşme, üretimden uzaklaşan eski üreticinin çare olarak gördüğg̈dür. Üretici konumundan tüketici konumuna geçmesi ise içinde bulunduğumuz ekonomik ve sosyal koşulların bir sonucudur. Tüketim kültürünün hâkim olduğu kapitalist bir düzen, çiftçisinden kentlisine kadar etkilidir. Dolayısıyla yaşanan göç de tüketim kültürüne uyumlanma zorunluluğunun bir sonucu olarak düşünülür.

Eski üreticinin tarımdan kopması ve kente uyum süreci, tüketimde bulunup bulunamaması ile ilgilidir. Dolayısıyla tarımdan kopmasının sebebi de tarımdan elde ettiği ürünü tüketmesi değil tüketim kültürünün ürünlerini tüketip tüketememesinden ileri gelmektedir. O halde eski üreticinin gida güvencesini sağlayabilmesi için sadece sebzesini değil aynı zamanda ihtiyacı olan tüm bileşenleri (et, süt, bakliyat vb.) üretmesi ya da doğal zamanında ürünlerine erişebilmesi gerekmektedir. Bireyin tek tip beslenmesine neden olacak olan üretim süreci, onun gida güvencesini sağlayamaması anlamına gelmektedir. Gıda güvencesinin sağlanması gerekir düşüncesiyle yola çıkıldığında üreticinin satın alma davranışı ile temel ihtiyaçlarını gidermesi gerekmektedir. Bu da üreticinin tüketim için nakit ihtiyacını ortaya çıkarmaktadır. 
Toplumların özellikleri, bireylerin davranışlarını da belirlemektir. Tüketim toplumlarında bireylerin toplumsal hayatta var olma biçimleri tüketimleri üzerinden gerçekleşmektedir. Tüketim toplumunun özelliği herkesin her şeye ulaşabilmesi ve her şeyi tüketebilmesi şeklinde düşünüldüğünde küçük üreticinin ürettiğini tüketmesi anlamsızlaşmaktadır. Neticede gıda güvencesi kavramının tanımından da anlaşılabileceği gibi çeşitli beslenme ürünlerinden yararlanılması gerekmektedir. Burada ihtiyaçtan fazlası gerekmekte, tükettikçe tüketim kültüründe var olunabilmektedir. O halde gıda güvencesi kavramının tüketim kültürüne paralel bir kavram olduğu söylenebilir. Fakat bu kavramın Türkiye özelinde üreticiye yansıması; iç göçleri hareketlendirmesi ve bireyleri tüketime yönlendirecek arayışlar içerisine girmesi anlamında anlamlıdır.

Türkiye'de üreticinin mülksüzleșerek tarım topraklarından ayrılması, yeni bir süreç değildir. Tarımda makineleşme ile başlayan göçler, günümüzde de devam etmektedir. Dikkat çeken nokta ise yeni kavramların ortaya çıkmasıdır. Örneğin tüketim kültürünün etkisiyle "tüketici" kavramı yeni bir boyut kazanmıştır. Bunun yanında yükselen bireyselleşme ve devletin üretici üzerinden el çekmesi ile üretici, kendi başının çaresine bakmak zorunda kalmıştır ayrıca küçük üreticinin karşısında artık küresel şirketler yer almaktadır. Küresel şirketlerin bu noktada küçük üreticinin ve topraksız köylünün üretim alanını kısıtladığı ve topraklarını ya da çalışma alanlarını ellerinden alarak onları mülksüzleştirdikleri de düşünülebilir.

Sonuç olarak Türkiye'de gıda güvencesi, tarım özelinde düşünüldügünde tüketim kültürü, mülksüzleşme, bireyselleşme, küreselleşme, iç göç ve kentleşme olgularıyla yorumlanmalıdır. Bu durum da gıda güvencesi kavramının sadece sağlığı ilgilendiren bir kavram olmadığını gerisinde karmaşık sosyolojik ilişkilerin bulunduğu bir durumu işaret etmektedir. Bu çalışma ile savunulan, Türkiye'de tarımda çalışan nüfusun yeterli gelir elde etmemesine rağmen tarımda çalışmaya devam etmesi değildir. Burada öne sürülen görüş, kente göç 
eden bireylerin, göç sonrasında da işsizlikle yüzleşebileceğidir. $\mathrm{Bu}$ sebeple ekonomik çalışmaların, kırsalda katma değer yaratacak başka faaliyetlere yönelik çalışmalarda bulunması gerekmektedir.

\section{Kaynaklar}

Açıl, Fethi (1957). Zirai Işsletmelerimiz ve Özellikleri. Ankara: Ankara Üniversitesi Basımevi, C.1.

Ağaç, Medeni (2011). Türkiye Hayvancıllk Sektöründe Glda Güvencesi Sorununun Kırmızı Et Örneğinde Incelenmesi. Yüksek Lisans Tezi. Bolu: Abant İzzet Baysal Üniversitesi.

Baudrillard, Jean (2004). Tüketim Toplumu. Çev: Hazal Deliceçaylı ve Ferda Keskin, İstanbul: Ayrıntı Yayınları.

Boratav, Korkut (1980). Tarımsal Yapılar ve Kapitalizm. Ankara: Ankara Üniversitesi.

Bozoğlu, Yasin (2018). "Yasal Düzenlemeler Çerçevesinde Türk Tarımının Yalnızlaştırılması ya da Yabancılaştırılması", https://www.academia.edu/35007771/Tar\%C4\%B1m\%C4\%B1n_Yaln \%C4\%B1zla\%C5\%9Ft\%C4\%B1r\%C4\%B1lmas\%C4\%B1_yada_Yaba nc\%C4\%B1la\%C5\%9Ft\%C4\%B1r\%C4\%B1lmas\%C4\%B1.pdf (Erişim Tarihi: 21.12.2018)

DİE (Devlet İstatistik Enstitüsü) (1973), Türkiye'de Toplumsal ve Ekonomik Gelişmenin 50 Yllı. Ankara: DİE Yayınları.

Erbaş, Mustafa ve Sultan Arslan (2015). “Açlığın Önlenmesi ve Gıda Güvencesinin Sağlanması”. TMMOB Gıda Mühendisliği Dergisi, S. 36, s. 51-59.

Hobsbawn, Eric (2007). Yeni Yüzyılın Eşiğinde, Söyleşi: Antonio Polito. Çev: İbrahim Yıldız. İstanbul: Yordam Kitap. 
Hürriyet Gazetesi (2018).

http://www.hurriyet.com.tr/yerel-haberler/antalya/antalyada-5-binciftci-tarimi-terk-etti-41008711 (Erişim Tarihi: 01.12.2018)

Iş1k, Oğuz ve M. Melih Pınarcioğlu (2012). Nöbetleşe Yoksulluk: Gecekondulaşma ve Kent Yoksullart: Sultanbeyli Örneği. İstanbul: İletişim Yayınları.

İTB (İstanbul Ticaret Borsas1) (2018).

https://itb.org.tr/dosya/rapordosya/-turk-tariminin-global-entegrasyonuve-tarim-40-pr.pdf? $\mathrm{v}=1552089600181$ (Erişim Tarihi: 15.02.2019)

Özer, İnan. (2004). Kentleşme, Kentlileşme ve Kentsel Değişme. Bursa: Ekin Kitabevi.

Kazgan, Gülten (1994). Yeni Ekonomik Düzende Türkiye'nin Yeri. İstanbul: Altın Kitaplar Yayınevi.

Keyder, Çağlar ve Zafer Yenal (2015). Bildiğimiz Tarımın Sonu. İstanbul: İletişim Yayınları.

Kıray, Mübeccel B. (1982). "Ereğli: A Ăır Sanayiden Önce Bir Sahil Kasabası”, Ankara: İletişim Yayınları.

Kıymaz, Taylan ve Ahmet Şahinöz (2010). "Dünya ve Türkiye - Gıda Güvencesi Durumu”. Ekonomik Yaklaşım, C. 21, S. 76, s. 1-30.

Koç, Mustafa (2013). Küresel Gıda Düzeni: Kriz Derinleşirken. İstanbul: Nota Bene Yayınları.

Koç Gökçe vd. (2018). "Gıda Güvencesini Hesaplama Yöntemleri ve Son Gelişmeler”. Conference: IX. IBANESS Congress Series. https://www.researchgate.net/publication/328228961_Gida_Guvencesin i_Hesaplama_Yontemleri_ve_Son_Gelismeler (Erişim Tarihi: 15.03.2019). 
Koyuncu, Ahmet (2011). 1980'den Sonra Kente Göç Edenlerin Tutunma Yollart: Konya Örneği. Doktora Tezi. Konya: Selçuk Üniversitesi.

Köymen, Oya (2008). Kapitalizm ve Köylülük: Ăgalar-ÜretenlerPatronlar. İstanbul: Yordam Kitap.

Magdoff, Fred (2015). "Dünya Gıda Krizi: Kaynaklar ve Çözümler”. Ekolojik Felaket ve Meta Olarak Gida. Der: Hakan Tanittıran. İstanbul: Kalkedon Yayınları, s. 39-59.

Owen, J.Robert (2005). "In Defence of the Peasants". Journal of Contemporary Asia, C. 35, S. 3.

Öktem, Vural A. (1966). "Türkiye'de Zirai İşletme Büyüklükleri ve Zirai Prodüktiviteye Tesiri", Ankara Üniversitesi SBF Dergisi. http://www.politics.ankara.edu.tr/dergi/pdf/21/2/5_A_Vural_Oktem.pdf (Erişim Tarihi: 14.03.2019).

Özkaya, Tayfun (1996). Türkiye Tarımında Küçük Üreticiler, Topraksızlar Sorunu ve İzmir İlinde Küçük ve Orta Büyüklükteki Tarım İşletmeleri Üzerine Bir Araştırma. İzmir: Ziraat Mühendisleri Odası İzmir Şubesi Yayınları.

Öztürk, Mustafa ve Nihat Altuntepe (2008). “Türkiye'de Kentsel Alanlara Göç Edenlerin Kent ve Çalışma Hayatına Uyum Durumları: Bir Alan Araştırması". Journal of Yaşar University. C. 3, S. 11, s. 15871625.

Shiva, Vandana (2014). Çalınmış Hasat: Küresel Gıda Soygunu. İstanbul: BGST Yayınları.

Teber, Serol (1980). Isş̧̧i Göçü ve Davranış Bozuklukları. Konuk Yayınları: İstanbul.

Topal, Aylin (2014). "Meksika'da Tarım Politikalarl ve Kırsal Mücadele Dinamikleri”. ODTÜ Gelişme Dergisi, C. 41, S. 2. 
http://www2.feas.metu.edu.tr/metusd/ojs/index.php/metusd/article/view 1683 (Erişim Tarihi: 15.03.2019).

TÜİK (Türkiye İstatistik Kurumu) (2017).

https://itb.org.tr/dosya/rapordosya/-turk-tariminin-global-entegrasyonuve-tarim-40-pr.pdf? v=1543568133282 (Erişim Tarihi: 20.12.2018).

Tütengil, Cavit Orhan (1975). 100 Soruda Kırsal Türkiye'nin Yapısl ve Sorunları. İstanbul: Gerçek Yayınevi.

www.yesilvadiarsaofisi.com.tr, "Trakya Bölgesi 2014 - 2023 Bölge Planı", $\quad$ https://www.yesilvadiarsaofisi.com.tr/trakyada-tarimdanfabrikalara-ic-goc-hizlandi/ (Erişim Tarihi: 11.12.2018)

Yalçın, Güneş E. vd. (2016). "Gıda Güvencesini Tehdit Eden Etmenler ve Çözüm Önerileri”. Nevşehir Bilim ve Teknoloji Dergisi, TARGID Özel Sayı, s. 130-134.

Yalçın, Güneş E. vd. (2016). "Kırsal Göç ve Tarımsal Üretime Etkileri". Harran Tartm ve Gida Bilimleri Dergisi, C. 2, S. 20, s. 154158.

Yıldırmaz, Sinan (2014). "Köylüler, İşçiler ve Köylü İşçiler". Toplumsal Tarih Dergisi, www.academia.edu/7323368/Köylüler İscciler ve Köylü-İsçiler (Erişim Tarihi: 12.12 .2018$)$

Uludağ Üniversitesi Fen-Edebiyat Fakültesi Sosyal Bilimler Dergisi Uludağ University Faculty of Arts and Sciences Journal of Social Sciences Cilt: 20 Sayl: 37 / Volume: 20 Issue: 37 


\section{EXTENDED ABSTRACT}

The subject of the study in point is the analysis of food security concept sociologically. The complexity of food security has been examined then. The respective concept personalizes the process while regarding the individuals as responsible in their health issues.

The study has started out from the definition of food security concept. The individual should carry out the principles such as 'availability', 'accessibility', 'acceptability' and 'sufficiency' to provide food security. While the individual should provide food security at first step here, the state should support him/her in cases where the induvial remains incapable with reference to principle of social state.

It's seen in the studies in which the sample of Turkey is analyzed that Turkey hasn't provided the food security. It's been considered in the researches conducted whether the principles mentioned have been carried out or not. In this case, the principles point at the ideal one to provide the food security. The ideal one has to be carried out as necessity or else unhealthiness will emerge, and this is something that needs to be examined.

The subject argued in the study is that there is also the effect of consumption culture on the individuals who move to cities quitting the production culture. Consumption culture does not get involved in the life of individual moving to city. Consumption culture indeed can be shown as the reason why the individual gave up farming and drifted apart from production process. The concept of consumption, as a result of the social structure in which we live, causes the producer pursue his/her desires which are beyond to meet the basic needs. The desire in question can be considered as an important reason of the individual's migration.

Furthermore, with the effect of neoliberal politics and globalization, the acts to possess fertile soil have also changed. There is no need for bloody wars for capitalist firms anymore. Therefore, strategies which are developed to take the soil away from the small producer have become significant. For instance, small producer is charged as in the study. The charge in question is carried out over seed and pesticide market.

The small producer who is charged in order to produce considers his/her abandoning the soil as deprivation of state aid. If the state aid to the small producer is cash, it can be easily presumed that loan will continue as the purchase of seed and pesticide goes on. The biggest reason for this situation is the genetically modified products which are used to get more efficiency from harvest. These products change 
the structure of the soil. Therefore, the producer is forced to loan to buy the same seed every year.

The group who is occupied with production without possessing soil can even experience domestic migration with the effects of technology while disconnection from production seems to be a problem of small producer. It has removed the difference between the peasants who have been deterritorialized while possessing soil and the peasants without soil by dispossession. The concept of 'peasant-worker' symbolizes a situation remaining in between. It is the reason of not being able to show the growth of western countries by the Turkish working class. The worker doesn't sell his/her land in the country side even if s/he moves to city and finds a job. This controversial case is the reason why there is an occurrence of the perception of a different working class from the one in the west. Therefore, the formation of working class essential for modernization has failed due to the occurrence of 'peasant-worker'. 'The peasantworker' has been able to fulfill individualization even it stays as an obstacle for modernization. They see that moving to cities as a result of individualization is the solution of financial problems and the way to fulfill the desires dictated by the consumption culture.

Consequently, it's evident that the concept of food security is not only about health. The tracks of consumption culture can be seen in the complexity of this concept. The individual will be able to get the common need, which is food, only by fulfilling certain requirements. There is no full nourishment that can be mentioned apart from this. There appears the matter of unhealthiness for the individual who is not able to meet the need to preserve products under certain conditions. Production remains in the background for the individual who is aware of the fact that one can survive through consumption in today's world dominated by consumption culture. It will especially lose attraction if production is estimated as unhealthy.

Uludağ Üniversitesi Fen-Edebiyat Fakültesi Sosyal Bilimler Dergisi Uludağ University Faculty of Arts and Sciences Journal of Social Sciences Cilt: 20 Sayl: 37 / Volume: 20 Issue: 37 